\title{
A study of medico-legal aspects of death due to burns at a tertiary care centre in Mumbai, India
}

\author{
Sunil Gorakh Vidhate ${ }^{1 *}$ and Harish Pathak ${ }^{2}$
}

\begin{abstract}
Background: Fire is a well-known double edged sword for human beings as it served as well as destroyed mankind. Death due to thermal burns is a burning topic all over the globe.

Material and method: A total of 109 cases of death due to fatal burns were brought for autopsy at a tertiary care centre in Mumbai, India during the period January 2014 to July 2015, were studied. A specially prepared proforma containing medico-legal aspects of death due to burns was filled. It was analysed by using Microsoft excel and tabulated for better understanding. Cases were studied with respect to marital status, alleged history of dowry death, manner of death, recording of dying declaration, history of psychiatric illness, chronic diseases, previous suicidal attempts etc., method of infliction of burn injury, inflammable substance, cause of death and survival period after burn injury infliction.

Results: Females were 92 in number (84.4\%) out of the 109 cases. Accidental deaths were 71 in number (65.14\%). In 12 cases (11.01\%), dying declaration was recorded by the police. Seven (6.42\%) suffered from psychitric illness while 6 (5.5\%) suffered from chronic systemic diseases. Sixty seven cases (61.47\%) died of septicemia while 42 (38. 53\%) died as a result of shock.
\end{abstract}

Keywords: Forensic sciences, Forensic medicine, Burns, Medico-legal aspects, Dying declaration

\section{Introduction}

Fire is mischievously called "necessary evil". (Sharma et al. 2006) Burn injuries have long been described as among the most serious injuries that may affect human body. (Nandy 2010) According to Ministry of Health and Family Welfare, Government of India database, approximately 70 lakh people sustain moderate to severe burns in India every year. (Government of India- Ministry of Health and Family Welfare n.d.) More than 7 lakh burn injuries require admission every year. (Government of India- Ministry of Health and Family Welfare n.d.) Around four out of five are women and children. These figures give idea about the burden caused by burn cases on health system in India. The burning topic in India is burn deaths of young newly married females for demand

\footnotetext{
* Correspondence: sunilvidhate95@gmail.com

${ }^{1}$ Department of Forensic Medicine and Toxicology, Government Medical

College and Hospital, Aurangabad, Maharashtra, India

Full list of author information is available at the end of the article
}

of dowry. (Satpathy 1995) Loss of such young population has led to adverse effect on country's development.

\section{Material and methods}

A prospective observational study was conducted considering 109 cases of death due to fatal thermal burns brought for autopsy at a tertiary care centre in Mumbai, India during the period of January 2014 to July 2015. Ethical permission was obtained from Institutional Ethics Committee of the study centre prior to the study onset.

A specially prepared proforma containing medico-legal aspects of the death due to burn was filled. It was analysed using Microsoft excel and tabulated for better understanding. All were studied with respect to marital status, alleged history of dowry death, manner of death, recording of dying declaration, history of psychiatric illness, chronic diseases, previous suicidal attempts etc., method of burn injury infliction, inflammable substance, cause of death and survival period after infliction of burn injury. 


\section{Observations and results}

Out of the total number of 109 cases, 92 (84.4\%) were females, where 77 (83.7\%) were married. Out of married female victims, $45(58.44 \%)$ died within 7 years and 10 $(12.99 \%)$ died within 7 to 10 years of marriage. Alleged history of dowry demand was recorded in 4 (5.19\%) cases among those who died within 7 years of marriage.

As for the manner of death, 71 cases $(65.14 \%)$ were accidental, 32 (29.36\%) were suicidal, 4 (3.67\%) were homicidal and $2(1.83 \%)$ were unknown. It was observed that in $12(11.01 \%)$ cases only dying declaration was recorded by police.

In Table 1, it was observed that, 7 cases (6.42\%) suffered from psychitric illness and 6 (5.5\%) suffered from chronic systemic diseases. Only $1(0.92 \%)$ victim had history of previous suicidal attempts and 10 (9.17\%) had a history of addiction to alcohol, tobacco chewing and smoking etc.

Accidental burns were mainly due to kerosene stove explosion (32 cases, 29.56\%) followed by suicidal burns where victims poured kerosene on themselves (31 cases, 28.44\%) (Fig. 1).

Use of accelerant to facilitate the burn injury is a common practice. It was observed that the use of inflammable substance was reported in 37 cases (33.94\%). When manner of death was considered in relation with use of accelerant, mainly suicides had used it in 28 cases (25.69\%). The smell of inflammable substance was perceived on post-mortem examination in 31 cases (28.44\%) (Table 2).

Cause of death was compared to survival time. It was seen that, 67 cases $(61.47 \%)$ died of septicemia and 42 (38.53\%) died as a result of shock within a week of burn injury infliction (Table 3).

\section{Discussion}

This study shows that the maximum number of victims were married females which is consistent with the studies done by Ambade and Godbole (2006), Batra (2003), Zanjad and Godbole (2007), Gupta and Srivastava (1988) and Tasgaonkar et al. (2015). This indicates the presence of social problems among married people, especially females, who have all household responsibilities. Also young and newly married females may become victim of dowry demand and domestic violence.

Table 1 Special considerations of burn deaths

\begin{tabular}{lllll}
\hline History & Male & Female & Total & Percentage \\
\hline Psychiatric illness & 3 & 4 & 7 & 6.42 \\
Chronic illness & 1 & 5 & 6 & 5.5 \\
Previous suicidal attempts & 1 & 0 & 1 & 0.92 \\
Addiction & 6 & 4 & 10 & 9.17 \\
NIL & 6 & 79 & 98 & 89.91 \\
Total & 17 & 92 & 109 & 100 \\
\hline
\end{tabular}

Among 77 (100\%) married females, 4 (5.19\%) were recently married for 6 months, 8 (10.39\%) were married for 6 months to 1 year, 33 (42.86\%) for $1-7$ years and 32 (41.56\%) for more than 7 years. Four (5.19\%) out of the 77 married females had alleged history of dowry demand; they were married for 1-7 years. No case was reported within 1 year of marriage with alleged history of dowry demand.

Incidence of allegations of dowry demand is low due to maximum number of urban victims and higher level of education. This might be due to the success of mass and social media in awareness of society regarding laws dealing with dowry deaths. On the contrary, in the study done by Nath et al. (2015), (57.40\%) of victims died within 7 years of marriage. In another study done by Verma et al. (2015), it was observed that $47.32 \%$ of the married female victims died within 7 years of marriage, out of which $15.84 \%$ were labelled as alleged dowry deaths.

The present study shows that, 71 (65.14\%) cases were due to accidental burns, 32 (29.36\%) were suicidal, 4 (3.67\%) were homicidal and the remaining 2 (1.83\%) were uncertain. This might be due to the fact that maximum victims are housewives and are more prone to accidental contact to fire while working in the kitchen, particularly in small and crowded houses. This is consistent with studies conducted by Zanjad and Godbole (2007), Gupta and Srivastava (1988), Tasgaonkar et al. (2015), Mangal et al. (2007) and Buchade et al. (2011). On the opposite side, these results are not consistent with the study done by Nath et al. (2015) which showed that maximum burn deaths were suicidal in nature, where 177 (81.94\%) were suicidal, 35 (16.20\%) were homicidal and 4 (1.85\%) were accidental. This study was performed in a tribal area where a different lifestyle and culture exists.

Dying declaration is "A written or verbal statement made by a person as to the cause of his or her death or as to the circumstances of transaction resulting in his or her death." (Mathiharan and Kannan 2012) It is a very important documentary evidence. (Gorea and Aggrawal 2004) It is a hearsay evidence but even then it is given a lot of weightage in court proceedings. (Gorea and Aggrawal 2004) Its admissibility in Court of Law has been explained under section 32(1) of Indian Evidence Act. (Kumar et al. 2014) The dying declaration was recorded in only 12 (11.01\%) out of 109 studied victims. All were recorded by police within 1-2 days of the incidence which is a low recording level. This might be due to the excessive number of cases and lack of awareness about its importance or simply due to the ignorance by administrative and investigating authorities. Being a tertiary care centre, most of the patients are referred in critical condition, often intubated or with tracheostomy which prevents investigating authorities from recording the declaration.

Among the victims, 7 (6.42\%) had a history of psychiatric illness of which $3(2.75 \%)$ were males and 4 




Fig. 1 Method of burn injury or source of fire

(3.67\%) were females. Six (5.5\%) suffered of chronic diseases of which $1(0.92 \%)$ was a male and $5(4.59 \%)$ were females. Also 10 had a history of addiction to alcohol, tobacco chewing and smoking etc., out of which, 6 (5.5\%) were males and 4 (3.67\%) were females. One victim had a history of previous suicidal attempts. Similarly, Akhter et al. (2010) observed psychiatric illness in $1.54 \%$ cases and chronic diseases in $5.18 \%$ cases. Chawla et al. (2010) observed alcoholism and addiction to smoking both together in $22 \%$ and only alcoholism in $2 \%$ of male victims whereas $2 \%$ female victims were smokers. In the study done by Leth and Saroc (1998), 51\% of house fire deaths were due to tobacco smoking in combination with alcoholism or handicap. This shows few problems related to urban lifestyle. These factors might predispose victims to fire related hazards. Awareness to the use of safety measures is impaired due to these conditions.

Kerosene stove explosion leading to accidental burns was observed in 32 cases (29.56\%) while 31 cases (28.44\%) had history of suicide by pouring kerosene themselves. Eighteen cases (16.51\%) had history of contact with flame while asleep or while lightening a lamp and in 10 cases (9.17\%) clothes caught fire. Among rest

Table 2 Distribution of cases according to inflammable substance

\begin{tabular}{lll}
\hline $\begin{array}{l}\text { Manner of } \\
\text { death }\end{array}$ & $\begin{array}{l}\text { History of use of } \\
\text { inflammable substance }\end{array}$ & $\begin{array}{l}\text { Smell of inflammable substance } \\
\text { perceived on autopsy }\end{array}$ \\
\hline Suicidal & 28 & 24 \\
Homicidal & 4 & 3 \\
Accidental & 5 & 4 \\
Total & 37 & 31 \\
Percentage & 33.94 & 28.44 \\
\hline
\end{tabular}

of accidental burns, 3 cases $(2.75 \%)$ were due to house fire, $2(1.83 \%)$ were due to gas stove explosion, 1 case (0.92\%) each was due to fall on kerosene stove, fall on gas stove and fall of lamp over the body. One case $(0.92 \%)$ had a history of suicide by pouring of diesel. Three $(2.75 \%)$ had alleged history of burning by their husbands where kerosene was used as an accelerant. This is consistent with studies done by Ambade and Godbole (2006), Gupta and Srivastava (1988), Chawla et al. (2010), Gupta et al. (1993) and Khartade et al. (2014). On the contrary, study done by Patetta and Cole (1990) reported burns by heating instrument in 33\% cases, smoking in $26 \%$ and cooking in $9 \%$ of the cases. The differences in observations may be due to different geographical areas and extent of awareness about safety measures.

Table 3 Distribution of cases as per causes of death and survival period

\begin{tabular}{lllll}
\hline $\begin{array}{l}\text { Duration of survival after } \\
\text { incidence }\end{array}$ & Shock & Septicaemia & Total & Percentage \\
\hline Brought dead & 6 & 0 & 6 & 5.5 \\
0 to $6 \mathrm{~h}$ & 1 & 0 & 1 & 0.92 \\
6 to $12 \mathrm{~h}$ & 7 & 0 & 7 & 7.34 \\
12 to $24 \mathrm{~h}$ & 10 & 0 & 10 & 9.17 \\
24 to $48 \mathrm{~h}$ & 10 & 2 & 12 & 11.01 \\
48 to $72 \mathrm{~h}$ & 4 & 4 & 8 & 7.34 \\
3 days to 7 days & 4 & 37 & 41 & 37.61 \\
7 days to 1 month & 0 & 20 & 20 & 18.35 \\
More than 1 month & 0 & 4 & 4 & 3.67 \\
Total & 42 & 67 & 109 & 100 \\
Percentage & 38.53 & 61.47 & & \\
\hline
\end{tabular}


History of use of inflammable substance to facilitate the fire was reported in 37 cases (33.94\%), of which 28 (25.69\%) were suicides, 5 (4.59\%) were accidents and 4 (3.67\%) were homicides. In accidental cases, the inflammable substance was accidently spread or used for some other purpose in surrounding. Kerosene is easily available and routinely used accelerant for household purposes. Use of diesel as an accelerant was characteristically noted in only one case. This is consistent with study done by Nath et al. (2015), where kerosene was used in 99.53\% cases. In study done by Khartade et al. (2014), sprinkling or pouring of kerosene over the body was observed in $24.81 \%$ victims of suicidal burns and $2.33 \%$ cases of alleged homicidal burns. Smell of inflammable substance was perceived on autopsy examination in total 31 cases (28.44\%). Out of these, 24 (22.02\%) were suicidal, 4 (3.67\%) were accidental and $3(2.75 \%)$ were homicidal. In study done by Chawla et al. (2010), smell of kerosene was perceived in 4\% cases. As the duration of hospital stay increases, the chances of perceiving smell of inflammable substance decreases due to their volatile nature and cleansing by the hospital staff.

Sixty seven $(61.47 \%)$ victims died due to septicemia while $42(38.53 \%)$ due to shock. All the victims that died due to septicemia had survived for more than $72 \mathrm{~h}$ while those who died due to shock, survived for less than $72 \mathrm{~h}$. Six (5.5\%) cases were brought dead after sustaining burn injury. Sharma et al. (2006) observed that $4.38 \%$ cases died due to neurogenic shock, $27.71 \%$ cases died due to hypovolemic shock and $67.91 \%$ cases died due to septicemia and its complications. Chawla et al. (2010) observed that $22 \%$ cases died due to primary shock, $10 \%$ died due to oligemic shock and $56 \%$ died due to septicemic shock and $12 \%$ died due to injuries. Dasari et al. (2013) had observed shock in 8\% case, toxaemia and shock in 18\% cases and septicemia in $71 \%$ cases of their study. Instantaneous death in case of burns is due to neurogenic shock. Death within the first $72 \mathrm{~h}$ is due to loss of fluid leading to hypovolemic shock. As the survival period and hospital stay increases, chances of infection increases leading to septicemia. On the contrary, Nath et al. (2015) observed shock as the cause of death in $65.74 \%$ and septicemia in $28.7 \%$ cases. In study done by Tasgaonkar et al. (2015), 3.38\% deaths were due to neurogenic shock, $36.38 \%$ cases due to oligemic shock, $29.54 \%$ cases due to septicemic shock and $30.46 \%$ cases due to acute tubular necrosis and complications of septicemia. In these studies, larger number of cases were declared dead before admission. Also duration of hospital stay was less than $72 \mathrm{~h}$ in maximum number of cases.

\section{Conclusion and recommendations}

1. Young and newly married females with household responsibilities are prone to sustain burn injuries. Safety measures should be followed while cooking. Social awareness is required to enroot the customs like dowry.

2. In most of the cases of death due to burn injury, accident is the alleged manner of death. Even though, manner of death is difficult to be guessed based on the pattern of burn injury, an attempt should be made by autopsy surgeon to comment on it.

3. Rate of recording of dying declaration in deaths due to burns is less than expected. This may be due to excessive number of cases and lesser number of staff. Administrative management and political will are required to increase the number and improve the quality of statement recorded.

4. Psychiatric illness, chronic diseases or addictions such as alcoholism may contribute to deaths by burn injuries. Proper counselling and consistent encouragement to improve quality of life of such persons may help to prevent suicides by burn injuries.

5. Kerosene is commonly available for household cooking and hence used by suicides as an accelerant. Smell of kerosene perceived on autopsy should be carefully noted as it serves an important evidence in court-of-law.

6. Shock and septicemia are the causes of death following burn injuries. Proper rehydration and prevention of hospital acquired infection is the key to prevent deaths in burn cases.

\section{Acknowledgements}

Not applicable.

Ethical approval and consent to participate

Received ethical approval prior to onset of the study from Institutional Ethics Committee at Seth G. S. Medical College and KEM Hospital, Mumbai, Maharashtra, India. Institutional Ethics Committee had granted waiver of consent to the present study.

Funding

Not applicable.

Availability of data and materials

Supporting data for present article is available with the authors.

Authors' contributions

Both the authors of present study has contributed equally in data collection, analysis and interpretation of the data. Both authors read and approved the final manuscript.

Consent for publication

Permission to publish anonymous data keeping in mind the privacy of individual was granted by Institutional Ethics Committee.

Competing interests

The authors declare that they have no competing interests.

\section{Publisher's Note}

Springer Nature remains neutral with regard to jurisdictional claims in published maps and institutional affiliations. 


\section{Author details}

'Department of Forensic Medicine and Toxicology, Government Medical College and Hospital, Aurangabad, Maharashtra, India. ${ }^{2}$ Department of Forensic Medicine, Seth G S Medical College and KEM Hospital, Parel,

Mumbai -12, India.

Received: 13 July 2017 Accepted: 12 November 2017

Published online: 21 December 2017

\section{References}

Akhter JM, Nerker NE, Reddy PS, Khan MI, Chauhan MK, Shahapurkar W (2010) Epidemiology of burned patients admitted in burn unit of a rural tertiary teaching hospital. Pravara Med Rev 2(4):11-17

Ambade VN, Godbole HV (2006) Study of burn deaths in Nagpur, Central India. Burns 32:902-908

Batra AK (2003) Burn mortality: recent trends and sociocultural determinants in rural India. Burns 29:270-275

Buchade D, Kukade H, Dere R, Savrdekar R (2011) Pattern of burn cases brought to morgue, Sion hospital Mumbai: a two years study. JIAFM 33(4):311-312

Chawla R, Chanana A, Rai H, Aggrawal AD, Singh H, Sharma G (2010) A two years burns fatality study. JIAFM 32(4):292-297

Dasari H, Kaur C, Singh A, Kumar A (2013) A comprehensive analysis of deaths due to burns in a tertiary care centre. J Punjab Acad Forensic Med Toxicol 13(2):68-73

Gorea RK, Aggrawal OP (2004) Critical appraisal of dying declaration. JAFM 26(1):24-26

Government of India- Ministry of Health and Family Welfare. Available from: http://mohfw.nicin/WriteReadData/892s/94668183Programme\%20website.pdf

Gupta RK, Srivastava AK (1988) Study of fatal burn cases in Kanpur (India). Forensic Sci Int 32(2):81-89

Gupta M, Gupta OK, Yaduvanshi RK, Upadhyaya J (1993) Burn epidemiology: the Pink City scene. Burns 19(1):47-51

Khartade HK, Keoliya AN, Ghormade PS, Tingne CV, Kumar NB (2014) Current trends in unnatural female deaths in central India. J Forensic Med Toxicol 31(1\&2):32-34

Kumar L, Kulbhushan CB, Kumar A (2014) Medicolegal aspects of dying declaration in India. JIAFM 36(3):281-283

Leth PM, Saroc GM (1998) Fatal accidents in housefires. Urgesklarger 160(23):3403-3408

Mangal HM, Pathak A, Rathod JS (2007) The fire is both a Blessing \& Scourge to the mankind. JIAFM 29(4):75-77

Mathiharan K, Kannan JK (2012) A textbook of medical jurisprudence and toxicology, 24th edn. LexisNexis, Nagpur

Nandy A (2010) Principles of forensic medicine including toxicology, 3rd edn. New central book agency, Kolkata

Nath A, Das P, Chakraborty PN (2015) Burnt wives of Agartala: a retrospective study from Medicolegal autopsies of a Tertiaty Hospital of Tripura, Northeast India: 2015. Int J Emerg Trends Sci Technol 2(7):2842-2846

Patetta MJ, Cole TB (1990) A population based descriptive study of housefire deaths in North Carolina. AJPH 80(9):1116-1117

Satpathy DK (1995) Burning brides-a Medicolegal study. J Med Law 14(7-8):547-552

Sharma BR, Harish D, Sharma A, Sharma S, Singh H (2006) Accidental burns in Indian kitchens: are they really accidental? JIAFM 28(1):14-17

Tasgaonkar GV, Zine KU, Meshram VP, Parchake MB, Sukhadeve RB, Hosmani AH (2015) Study of trends of burn deaths at Aurnagabad region in India. Sch J App Med Sci 3(5C):2013-2018

Verma RK, Shrivastava PC, Sinha US, Kaul A (2015) Study of unnatural deaths in married females within seven years of marriage in Allahabad. JIAFM 37(4):405-409

Zanjad NP, Godbole HV (2007) Study of fatal burn cases in medico- legal autopsies. JIAFM 29(3):42-49

\section{Submit your manuscript to a SpringerOpen ${ }^{\circ}$ journal and benefit from:}

- Convenient online submission

- Rigorous peer review

- Open access: articles freely available online

- High visibility within the field

- Retaining the copyright to your article 